\title{
A Simple Approach for Measuring FRET in Fluorescent Biosensors Using Two-photon Microscopy
}

\author{
Richard N. Day ${ }^{1 *}$, Wen Tao ${ }^{2}$, Kenneth W. Dunn ${ }^{2}$ \\ ${ }^{1}$ Department of Cellular and Integrative Physiology; Indiana University School of Medicine; \\ 635 Barnhill Dr., Indianapolis, IN USA \\ ${ }^{2}$ Department of Medicine; Division of Nephrology; Indiana University Medical Center; \\ Indianapolis, IN USA \\ ${ }^{*}$ Correspondence should be addressed to RND. \\ Voice: (317) 274-2166 \\ Email: rnday@iupui.edu
}

DOI: nprot.2016.121

\section{Figures: 6}

Tables: 2

Boxes: 1

CFI: none

\section{SI: Supplementary Sequence Archive}

Editorial summary: This Protocol describes a simple pipeline for imaging FRET biosensor probes with two photon laser scanning microscopy (TPLSM). Validated FRET standards are described that can be used with any TPLSM setup to ensure sensitive detection of FRET ratios.

This is the author's manuscript of the article published in final edited form as: Day, R. N., Tao, W., \& Dunn, K. W. (2016). A simple approach for measuring FRET in fluorescent biosensors using two-photon microscopy. Nature Protocols, 11(11), 2066-2080. http://doi.org/10.1038/nprot.2016.121 
Proposed Tweet: \#NewNProt: Simplified use of \#FRETbiosensor probes in

\#TwoPhotonMicroscopy [LINK] \#TPLSM \#FRET

\section{Proposed Ontology}

Biological sciences / Biological techniques / Optical spectroscopy / Fluorescence resonance energy transfer

Biological sciences / Biophysics / Biological fluorescence

Biological sciences / Cell biology / Cell signalling

Biological sciences / Biological techniques / Microscopy / Multiphoton microscopy

Biological sciences / Biological techniques / Sensors and probes

Keywords: two photon laser-scanning microscopy, TPLSM, Förster resonance energy transfer, FRET, fluorescent protein, biosensor probe, PKA activity

\section{Supporting primary paper:}

Tao, W. et al. A practical method for monitoring FRET-based biosensors in living animals using two-photon microscopy. Am J Physiol Cell Physiol 309, C724-35 (2015). DOI: 10.1152/ajpcell.00182.2015

\section{Permissions required for:}

Figures 3, 4, 5 and 6. 


\begin{abstract}
Genetically encoded fluorescent protein (FP)-based biosensor probes are useful tools for monitoring cellular events in living cells and tissues. Because these probes were developed for one-photon excitation approaches, their broad two-photon excitation (2PE) and poorly understood photo-bleaching characteristics have made their implementation in studies using two-photon laser-scanning microscopy (TPLSM) challenging. Here, we describe a protocol that simplifies the use of Förster Resonance Energy Transfer (FRET)-based biosensors in TPLSM. First, the TPLSM system is evaluated and optimized using FRET standards expressed in living cells, which enables the determination of spectral bleedthrough and the confirmation of FRET measurements from the known standards. Then, we describe how to apply the approach experimentally using a modified version of the AKAR protein kinase A (PKA) biosensor as an example, first in cells in culture, and then in hepatocytes in the liver of living mice. The microscopic imaging can be accomplished in a day in laboratories that routinely use TPLSM.
\end{abstract}




\section{INTRODUCTION}

The use of TPLSM imaging to monitor the signals from biosensor proteins in living animals is of interest to many laboratories because it allows noninvasive detection of spatial and temporal characteristics of specific cell signaling or metabolic events. These genetically encoded biosensor proteins contain reporter modules that typically consist of fluorescent proteins (FPs) directly linked to sensing units that detect specific cellular events ${ }^{1}$. Many biosensor probes rely on Förster resonance energy transfer (FRET) to report the changes in protein conformation that occur in response to the cellular event ${ }^{1-6}$. There are, however, significant challenges to the use of TPLSM to detect the FRET signals from biosensor probes in intact tissues, which fall into three general categories: 1) issues related to the two-photon excitation (2PE) characteristics of the biosensor probes, 2) difficulties in expressing the genetically encoded biosensors in the desired cell-type in living animals, and 3) problems associated with conducting high-resolution microscopy in living animals. These three challenges are discussed further below, but this Protocol specifically addresses the first issue: identification, characterization, and validation of a FRET-based FP biosensor suitable for TPLSM in intact tissues.

1) Optimized probes for TPLSM. Many existing biosensor probes that were developed for one-photon excitation may perform poorly (or not at all) under 2PE. Even those probes that perform well under 2PE may not be efficiently excited by the narrow range of wavelengths accessible with the titanium sapphire lasers used in most TPLSM systems (tunable from 690 to $1040 \mathrm{~nm}$, but peaking between 750 and $850 \mathrm{~nm}$ ). Many biosensor assays are based upon ratiometric measurements of images collected using two different excitation wavelengths. This complicates measurements by TPLSM because most FPs have broad two-photon cross-sections, 
limiting the ability to selectively excite one or the other FP. Furthermore, most TPLSM systems are equipped with a single infrared laser, so the collection of ratiometric FRET measurements may require re-tuning of the laser between image acquisitions; a process that is slow (precluding dynamic studies), and introduces measurement errors because of changes in laser alignment. Finally, photobleaching processes that occur under 2PE are poorly understood. Unlike single-photon excitation, the rate of photobleaching under 2PE increases exponentially with illumination power, sometimes increasing with the $3^{\text {rd }}$ or $4^{\text {th }}$ power of the illumination level ${ }^{7,8}$. Since differences in the susceptibility of the donor- and acceptor-FPs to photobleaching could affect ratiometric measurements, it is particularly important to use FPs that are photostable and free from photo-switching behavior.

2) In vivo expression of FP biosensors. The sequences that encode the biosensor probes are easily incorporated into plasmid or viral vectors that allow their transfer into living cells or organisms. The use of suitable cell-type specific promoters can restrict the expression of the biosensors to specific tissues, and the probes can be directed to specific subcellular organelles by incorporating suitable targeting sequences. The fluorescence signals from biosensor probes have been successfully imaged in a wide variety of organisms. For example, transgenic $C$. elegans, Drosophila, and Zebrafish have been generated that express calcium sensing biosensor proteins $^{9-11}$. In general, the imaging of biosensor activities in transgenic mice, however, has proven to be more difficult ${ }^{12}$. A problem often encountered with transgenes stably integrated in mice is low-level expression resulting from transgene silencing or recombination events that occur between the highly homologous sequences encoding the sensor FPs ${ }^{13,14}$. Transgenic mice generated by transposon-mediated gene transfer methods have been reported to have higher levels of biosensor expression ${ }^{13-15}$. Transgenic biosensor mice that express a variety of different 
probes, including sensors of chloride ${ }^{16}$, calcium ${ }^{17,18}$, and voltage ${ }^{19}$, are available commercially (The Jackson Laboratory, Bar Harbor, ME) and might be useful for specific intravital imaging applications. Transgenic mice expressing fluorescent biosensors for PKA, Erk, Rac, Ras are also available from the National Institutes of Biomedical Innovation, Health and Nutrition (Osaka, Japan). Further, there are published studies reporting transgenic biosensor mice with ubiquitous tissue distribution ${ }^{13,19}$, or restricted tissue expression ${ }^{12}$. The critical question for investigators is whether the biosensor expression is sufficiently high in the desired tissue in a particular mouse model to obtain unambiguous measurements of changing cell signaling events $^{12}$.

Viral transduction is an alternative approach that offers rapid biosensor probe expression in living animals without the need for lengthy breeding strategies to achieve stable expression. The challenge for in vivo administration of viral vectors, however, is to obtain expression of the biosensor probes in the relevant cell types. The expression of probes in a particular tissue can be achieved using cell-type specific promoters that restrict the biosensor expression to the target cells. However, if the cells of interest can be identified based on morphology, it might not be necessary to achieve selective expression in specific cell populations. Further, the systemic administration of unmodified adenovirus (Ad) generally results in the accumulation of the transgene in the liver and spleen ${ }^{20}$, so the tropism to these organs can be exploited for imaging studies.

3) High resolution microscopy in living animals. Intact, living organisms present unique challenges for microscopy. First, the physiological welfare of the animal must be maintained and continuously monitored while the animal is on the microscope stage. Second, in most cases, the tissue of interest must be surgically exposed, requiring the development of methods 
for anesthesia and delicate surgery. Third, the tissue must be immobilized so that motion induced by respiration and the heartbeat is reduced to sub-micron levels.

The solutions to these challenges vary depending on the equipment used and the particular organ to be imaged. In our studies of kidney and liver ${ }^{21-24}$, an inverted microscope stand is used to image the surgically exposed organs that are secured to a glass-bottomed dish (see Figure 1). The anesthetized animal is placed on the microscope stage, and the animal's temperature is maintained using a heating pad and monitored using a rectal thermometer. Generally, tissue motion can be minimized by careful placement of the tissue, and can be reduced further by bonding small regions of the tissue to the coverglass with cyanoacrylate adhesive. Additionally, gating the image collection to respiration can minimize the motion artifacts in tissues such as the lung ${ }^{25,26}$. Finally, motion-induced distortions can be eliminated from the collected images using various methods of digital image analysis ${ }^{27-31}$.

Quantitative intravital microscopy is also complicated by the inevitable loss of signal that occurs when imaging into highly scattering biological tissues. Therefore, the intensity measurements obtained from different depths cannot be directly compared. In this regard, using FRET-based biosensors can be advantageous. The ratio images obtained from biosensors will be minimally affected by depth provided that the scattering and absorption does not vary significantly for the emission wavelengths of the probe. While we find no evidence of a significant effect of depth on FRET measurements obtained in vivo, minor effects were observed in other studies ${ }^{32}$. Therefore, biosensor measurements collected over a large range of depths should be evaluated for systematic effects of depth on the FRET ratio. In general, the effects of depth on ratiometric measures can be minimized by using non-descanned detectors 
that are less susceptible to the effects of light scatter, and by avoiding FPs with widely different emission spectra.

\section{Development of the Protocol}

Previously, we described the characterization of FPs for FRET biosensor probes specifically intended for intravital imaging using TPLSM ${ }^{33}$. Since the cyan FPs (CFP) are optimally excited close to the power maximum of the titanium-sapphire lasers used in most TPLSM systems, we focused our evaluations of potential FRET donors on the newer variants of the CFPs that have improved brightness and photostability, and no photo-switching behavior ${ }^{34-37}$. Based on previous studies demonstrating that wavelengths near $800 \mathrm{~nm}$ could be used for relatively selective excitation of CFP over YFP ${ }^{38,39}$, we focused our evaluations of potential FRET acceptors on newer, improved variants of YFP. Based on these studies, we identified monomeric (m)Turquoise ${ }^{35}$ and mVenus $^{40}$ as optimal FPs for TPLSM. We found that illumination at $810 \mathrm{~nm}$ efficiently excited mTurquoise with minimal direct excitation of mVenus $^{33}$. The selective excitation of mTurquoise at $810 \mathrm{~nm}$ allows ratiometric FRET measurements in vivo using TPLSM at a single excitation wavelength. Moreover, the use of the cyan and yellow FPs is compatible with most TPLSM configurations.

A critical step in the acquisition of measurements from FRET-based biosensors is validation of the sensitivity of the method. It is necessary to demonstrate that measurements of subtle changes in the FRET ratio truly reflect the responses of the biosensor to cellular events. In general, FRET measurements should be reproduced using multiple methods. For example, FRET estimates based on measurements of sensitized emission should be complemented with estimates from acceptor photobleaching or fluorescence lifetime measurements ${ }^{33}$. Given the 
inherent challenges of intravital microscopy our goal was to develop a protocol that would minimize the validation studies that must be conducted. We accomplish this by providing a set of completely validated FRET standards, and a simple method by which the end-user can characterize and optimize FRET measurements in their own systems.

\section{Overview of the Procedure}

Here, we describe a protocol in which a TPLSM system can be optimized and validated for FRET measurements in studies of cultured cells, prior to studies in living animals (see Figure 2). We demonstrate intravital FRET biosensor imaging using an A kinase activity reporter (AKAR) biosensor of PKA activity, expressed by adenoviral transduction of the mouse liver. Our approach to intravital measurements of FRET-biosensor activity involves four stages: (i) characterization of the emission spectra and the determination of spectral crosstalk correction factors for the donor and emission FPs in the user's system; (ii) validating the experimental system for measuring FRET using FRET standards expressed in cells in culture; (iii) validation of the FRET-biosensor for measurements from cells in culture; (iv) measurement of FRETbiosensor responses in cells in living animals.

Measurement of spectral crosstalk correction factors. The imaging protocol described here exploits the relatively selective $2 \mathrm{PE}$ of mTurquoise ${ }^{35}$ over mVenus ${ }^{40}$ using illumination at 810 $\mathrm{nm}$, which enables the measurement of FRET ratios from single, two-channel images (Figure 3). The accurate measurement of FRET efficiencies (EFRET), however, requires the application of correction factors for spectral crosstalk (Box 1). These correction factors are entirely dependent upon the configuration and performance of the microscope system, and must be measured for each system. 
Characterization and validation of FRET measurements using FRET standards. The FRET standards are critical tools for verifying both the biological model and for optimizing the particular imaging system used for FRET measurements ${ }^{46}$. By providing a range of calibrated, reproducible EFRET, the FRET standards allow the user to evaluate the performance of the system for the detection of FRET, and importantly, allow an assessment of the sensitivity of the measurements (described in Anticipated Results). We have developed plasmids for a set of fully validated FRET standards, based upon mTurquoise and mVenus (see Figure 2, sequence information is provided in the Supplementary Sequence Archive, plasmids available from authors on request). Measurements of EFRET obtained from living cells expressing these standards (using the approach described in Box 1) are used to validate and optimize the user's system for detection of FRET in mTurquoise-mVenus-based biosensors.

Validation of the FRET biosensor probe activity in cultured cells. To verify and fully characterize the performance of the FRET biosensor in the user's system, preliminary studies are conducted in cultured cells, which can be manipulated to identify the full range of FRET ratios provided by the biosensor under physiological conditions. Here, an AKAR biosensor ${ }^{47,48}$ with a reporter module consisting of mTurquoise and circular permuted (cp)Venus FPs $(\text { AKAR4.1) })^{33}$ is used to monitor PKA activity in living cells. The response of the AKAR4.1 probe expressed in cells treated with a specific PKA agonist is used to characterize the performance of the system for measurements of changing FRET ratios.

Measurements of biosensor probe activity in the living animal. Once the imaging system has been validated using the FRET standards, and the performance of the biosensor has been verified in living cells in culture, the final step is to apply the information collected in the in vitro studies to use the FRET probe to assay cellular function in the living animal. We use the 
expression of Ad AKAR4.1 in the mouse liver to demonstrate the use of this protocol to measure the activity of the PKA pathway in vivo.

\section{Limitations of the approach}

The protocol described here is designed for compatibility with the commonly available commercial TPLSM systems equipped with a single Titanium-sapphire laser, and detection pathways compatible with the emission spectra of cyan and yellow FPs. We recognize that investigators may conduct their TPLSM studies on a shared instrument where the nondescanned detectors may not be configured for the efficient collection of cyan and yellow fluorescence. In this situation, it may be necessary to use the descanned detectors that are typically easier to configure. Since descanned detectors are located far from the back aperture of the objective, they collect less of the fluorescence scattered in the tissue, and thus provide poorer reach into biological tissues than non-descanned detectors located adjacent to the back aperture of the objective. The ideal design for a system dedicated to 2PE FRET studies would be one in which the non-descanned pathway was fitted with filters optimized for sensitive and specific detection of mTurquoise and mVenus.

In addition, the objective lenses used to obtain subcellular resolution provide a field of view that is typically less than a millimeter across. Therefore, it can be difficult to draw general conclusions about cellular function based upon observations collected within such a tiny window. More significantly, the microscope samples only the most superficial layers of biological tissues. Even TPLSM, which allows deeper imaging than confocal microscopy, is generally limited to depths of less than 100 microns into tissue. Thus, TPLSM is incapable of analyzing populations of cells located deep in organs (e.g., renal medulla) or to evaluate physiological properties below the surface of tumors. 
Finally, the intravital setting presents significant challenges to the expression of fluorescent biosensor probes. Here, we use Ad transduction to achieve high level expression of a biosensor probe in the liver of mice. The Ad provides robust, but transient, expression of the transgenes. Further, there are typically inflammatory responses to the virus that can limit its use in prolonged studies. These problems are largely overcome by adeno-associated virus (AAV) or lentivirus vectors, which can achieve persistent transgene expression with minimal inflammatory responses. Importantly, there are many serotypes of AAV that differ in their capsid protein structures, and this enables distinct tissue tropism for the different serotypes ${ }^{20,41}$.

\section{Advantages}

A crucial component of this protocol is the use of the well-characterized FRET standards as a tool to validate that both the experimental model and microscope system are optimized for sensitive measurements of FRET (see Anticipated Results). Therefore, it is necessary that the end user determines the corrected FRET efficiency for each of the standards to assess the performance of their system, and to compare their results with those obtained here (or from other studies if different standards are used). The measurement of the FRET standards on the microscope system enables confirmation of the ratiometric FRET measurements acquired in vivo using the single wavelength $2 \mathrm{PE}$ of the biosensor probes. The acquisition of single, two-channel images with TPLSM simplifies image collection, maximizing temporal resolution, and minimizing the number of in vivo studies. The use of a single wavelength for $2 \mathrm{PE}$ offers additional advantages for the measurement of biosensor probe activity in intact tissue, avoiding the delay in the collection of ratio images and the effects of shifts in laser alignment at different wavelengths. 
Several groups have described the use of fluorescence lifetime imaging as an effective approach for measuring FRET in vivo ${ }^{42-44}$. The ratiometric approach offers a few key advantages over fluorescence lifetime-based approaches. First, it is easily implemented in most TPLSM systems, requiring no additional instrumentation. Second, the ratiometric approach provides better temporal resolution; whereas fluorescence-lifetime measurements typically require image collection over tens of seconds, images for ratiometric measurements can be collected in less than a second.

We demonstrate the use of our approach to measure PKA activity in vivo. However, we emphasize that this approach should be generalizable to other FRET-based biosensors, once the reporter module is modified to include mTurquoise and suitable acceptor. For example, we have found very similar results using the optimized calcium biosensor probe, Twitch $2 \mathrm{~b}^{45}$. Thus, with minimal effort the approach described here could be applied to many other biosensor probes by exchanging the earlier, more photo-labile, variants of the cyan FPs.

\section{MATERIALS}

\section{REAGENTS}

- Dulbecco's Modified Eagle's Medium (DMEM, Fisher Scientific Inc. Cat. \# 50-188-267FP)

- Dulbecco's Modified Eagle's Medium without phenol red (Fisher Scientific Inc. Cat. \# MT17205CV)

- Fetal bovine serum (FBS, Atlanta Biologicals. Cat. \# S11150)

- Trypsin (Fisher Scientific Inc. Cat. \# MT25-051-Cl, stored at -20 C). 
- X-tremeGene HP DNA transfection reagent (Roche Diagnostics, Indianapolis, IN, Cat. \#06366236001, made up fresh).

- Appropriate biosensor construct. In the Procedure, we use the Adenovirus (Ad) CMV-TurqAKAR4 vector as an example, which was made as described previously ${ }^{49}$ (see Supplementary Sequence Archive).

- HEK-293 cells (ATCC CRL-1573) Caution! - HEK-293 cells contain Adenovirus 5 DNA integrated into chromosome 19 and must be handled at Biosafety level 2. The cell lines used in your research should be regularly checked to ensure they are authentic and are not infected with mycoplasma.

- FP constructs. See Table 1. All FP constructs described here are available through the National Institutes of Health O'Brien Center for Advanced Renal Microscopic Analysis at Indiana University School of Medicine. The plasmid sequences can be found in Supplementary Sequence Archive.

Table 1: FP constructs required in the Procedure.

\begin{tabular}{|l|l|l|}
\hline Plasmid construct & Purpose & Additional comments \\
\hline mTurquoise N1 & to determine donor spectral & \\
\hline mVenus N1 & to determine acceptor & \\
\hline Turquoise-TRAF-Venus & Sectral bleedthrough & Turquoise is separated from \\
(TTRAFV) & standard and is used to & Venus by the TRAF2 \\
& determine fractional & sequence. ${ }^{46}$ Typical EFRE is \\
& excitation of Venus. & $5-10 \%$. \\
\hline
\end{tabular}




\begin{tabular}{|l|l|l|}
\hline Turquoise-10aa-Venus & Serves as an intermediate & $\begin{array}{l}\text { Turquoise is separated from } \\
\text { Venus by the sequence }\end{array}$ \\
& FRET standard. & "SGLRSPPVAT". Typical \\
& EFRET is 30-35\%. \\
\hline Turquoise-5aa-Venus (T5V) & Serves as a high FRET & Turquoise is separated from \\
& standard. & Venus by the sequence \\
& "SGLRS". Typical FRET \\
& efficiency (EFET) is 40-45\%. \\
\hline Turquoise AKAR4.1 & Biosensor probe to detect & The AKAR4 biosensor \\
& protein kinase A activity. & with Turquoise as the donor \\
fluorophore.
\end{tabular}

- Mice: Caution! - Any experiments involving live mice must conform to relevant Institutional and National regulations. All animal studies were approved by the Indiana University School of Medicine Institutional Animal Care and Use Committee and conform to the "Guide for the Care and Use of Laboratory Animals" published by the National Institutes of Health (NIH Publication No. 85-23, Revised 1996).

\section{EQUIPMENT}

- Laser scanning microscope compatible with two-photon excitation at $810 \mathrm{~nm}$ and two channel fluorescence detection in the approximate ranges of $454-494 \mathrm{~nm}$ for detection of mTurquoise and $520-580 \mathrm{~nm}$ for detection of mVenus. Our system is described in Equipment Setup. 
- Image processing software capable of quantifying signal levels in user-identified regions of interest, such as ImageJ (https://imagej.nih.gov/ij/), Metamorph (https://www.moleculardevices.com/), or the microscope manufacturer's software.

- A laser power meter to measure the power at the specimen plane (PM100D power meter, Thorlabs, Newton, NJ).

\section{REAGENT SETUP}

HEK-293 cells: Human embryonic kidney (HEK)-293 cells are maintained in monolayer culture in Dulbecco's Modified Eagle's Medium (DMEM) containing 10\% (vol/vol) fetal bovine serum (FBS) at $37^{\circ} \mathrm{C}$ in a $5 \%(\mathrm{vol} / \mathrm{vol}) \mathrm{CO}_{2}$ incubator, and harvested at $80 \%$ confluence by treatment with Trypsin. The $\mathrm{pH}$ indicator dye Phenol red may cause background signals during imaging. Therefore, prior to imaging the medium should be replaced with the same medium lacking the indicator.

\section{EQUIPMENT SETUP}

Intravital microscope system. In our lab, IVM is conducted as previously described ${ }^{24}$ using a modified Olympus FV1000 spectral laser-scanning confocal microscope system, mounted on an Olympus IX81 stand, and modified for two-photon excitation. Near-infrared illumination, provided by a MaiTai HP Ti-sapphire laser (Spectra-Physics, Santa Clara, CA) is attenuated using a Pockels cell electro-optical attenuator (Conoptics Inc., Danbury, CT), and the beam is expanded via a Keplerian collimator/beam expander. Images are acquired using an Olympus 25X, NA 1.05 XLPN water immersion objective (see Figure 1). Fluorescence is collected using the Olympus FV1000 photomultiplier detectors on the descanned detection pathway. The 
FV1000 spectral detection system (spectral grating) is used to collect spectral data and to select emission wavelengths optimized for each fluorescent protein. Laser power at the specimen plane is measured using a PM100D power meter, Thorlabs, Newton, NJ).

\section{PROCEDURE}

1) Transfection of cells with mTurquoise and mVenus plasmids. $18-24 \mathrm{~h}$ before transfection, plate cells HEK-293 cells in $500 \mu$ complete growth medium at a density of $3.0-3.5 \times 10^{5}$ cells/well in 4-well Lab-Tek II chambered coverglasses. Incubate cell cultures overnight in a $5 \%$ (vol $/ \mathrm{vol}) \mathrm{CO}_{2}$ incubator. The cells should be $50-85 \%$ confluent at the time of transfection, and each transfection should be performed in duplicate.

2| Allow X-tremeGENE HP DNA Transfection Reagent, DNA and diluent (Opti-MEM. I Reduced Serum Medium or serum-free medium) to warm to room temperature $\left(\sim 21^{\circ}\right.$ C), and gently mix.

3| For each transfection, place $300 \mu \mathrm{l}$ diluent in a sterile tube.

4| Add $3 \mu \mathrm{g}$ of the appropriate plasmid DNA (see table below) to each transfection mix. Pipet gently to mix.

\begin{tabular}{|l|l|l|}
\hline Transfected & $\begin{array}{l}\text { Step at which } \\
\text { transfection }\end{array}$ & Purpose \\
performed & \\
\hline mTurquoise & 4 & Determining optimal \\
\hline
\end{tabular}




\begin{tabular}{|c|c|c|}
\hline & & $\begin{array}{l}\text { settings for detection } \\
\text { (step 11) and spectral } \\
\text { bleedthrough (step } \\
13 \text { ) }\end{array}$ \\
\hline mVenus & 4 & $\begin{array}{l}\text { Determining optimal } \\
\text { settings for detection } \\
\text { (step 11) and spectral } \\
\text { bleedthrough (step } \\
\text { 13) }\end{array}$ \\
\hline $\begin{array}{l}\text { mTurquoise + } \\
\text { mVenus }\end{array}$ & 4 & $\begin{array}{l}\text { Determining } \\
\text { fractional excitation } \\
\text { at 810nm (step 16) } \\
\text { and EFRET (step 21) }\end{array}$ \\
\hline $\begin{array}{l}\text { Turquoise-TRAF- } \\
\text { Venus (TTRAFV) }\end{array}$ & 4 & $\begin{array}{l}\text { Determining } \\
\text { fractional excitation } \\
\text { at } 810 \mathrm{~nm} \text { (step 16) } \\
\text { and EFRET (step 21) }\end{array}$ \\
\hline $\begin{array}{l}\text { Turquoise-5aa- } \\
\text { Venus (T5V) }\end{array}$ & 4 & $\begin{array}{l}\text { Determining EFRET } \\
\text { (step 21) }\end{array}$ \\
\hline $\begin{array}{l}\text { Turquoise-10aa- } \\
\text { Venus (T10V) }\end{array}$ & 4 & $\begin{array}{l}\text { Determining EFRET } \\
\text { (step 21) }\end{array}$ \\
\hline $\begin{array}{l}\text { AKAR4.1 biosensor } \\
\text { (or probe of interest) }\end{array}$ & 4 & $\begin{array}{l}\text { Biosensor probe for } \\
\text { measurement of PKA }\end{array}$ \\
\hline
\end{tabular}




\begin{tabular}{|l|l|l|}
\hline & activity (step 27). \\
\hline
\end{tabular}

5| Add $9 \mu \mathrm{l}$ X-tremeGENE HP DNA Transfection Reagent to the diluted DNA. (3:1 ratio of reagent to DNA). Pipet gently to mix.

6| Incubate for $15-30 \mathrm{~min}$ at room temperature.

7| Add $75 \mu 1$ of the appropriate transfection complex to cells in a drop-wise manner.

8| Gently shake chambered coverglass to ensure even distribution, and then incubate the cells at $37^{\circ} \mathrm{C}$ in a $5 \%(\mathrm{vol} / \mathrm{vol}) \mathrm{CO}_{2}$ for $24-48 \mathrm{~h}$ before imaging.

System evaluation and optimization - determine the spectral ranges for the detectors (1.5-

2 hrs)

9| Prepare TPLSM system. At least 30 minutes prior to image acquisition, turn on the system according to the manufacturer instructions, to ensure that power and alignment are completely stabilized prior to image collection. Tune and align laser at $810 \mathrm{~nm}$. CRITICAL STEP: Allow the laser to warm and stabilize for $\sim 30 \mathrm{~min}$ before imaging to ensure the system is consistent for image collection.

10| Prepare to collect images for measurement of spectral bleedthrough (SBT). $24-48 \mathrm{~h}$ after transfection of cells with mTurquoise or mVenus (at step 4), transfer transfected cells (from step 8) into a medium suitable for maintaining physiological $\mathrm{pH}$ in air, or into a chamber capable of maintaining $5 \%$ (vol/ $/ \mathrm{vol}) \mathrm{CO}_{2}$ environment. Mount cells in a stage incubator set to maintain cells at 37 degrees $\mathrm{C}$.

11 Optimize the microscope settings for optimal detection of mTurquoise and mVenus emissions. Users with filter-based systems should follow Option A. Users with spectral 
fluorescence detectors should follow Option B to determine the spectral range settings for the imaging system..

CRITICAL STEP: The SBT components that contaminate the FRET signal result from the donor (mTurquoise) emission that bleeds into the acceptor detection channel (DSBT), and the direct excitation of the acceptor (mVenus) at the donor excitation wavelength (ASBT). It is necessary to correct for SBT in order to accurately determine FRET efficiency. The SBT corrections are specific to each microscope system, and are entirely dependent on spectral or filter settings on the microscope, so it is critical to always verify these settings on multi-user microscope systems.

\section{(A) Verification of the set-up of filter-based systems}

(i) Select the correct emission filters for the cyan and yellow channels, and the appropriate dichroic mirror.

(ii) Measure the signal from the cells expressing mTurquoise only and from cells expressing mVenus only (from step 8 ) to verify that the correct emission filters and dichroic mirrors are being used.

\section{(B) Optimizing systems with spectral fluorescence detectors}

(i) Using cultured cells expressing mTurquoise only and cells expressing mVenus only (from step 8 ), set the illumination to $810 \mathrm{~nm}$, adjust illumination levels to fill the dynamic range of the detectors without saturation and collect emission scans from approximately $420-600 \mathrm{~nm}$. 
(ii) Evaluate the emission spectra of mTurquoise and mVenus and identify the optimal wavelength ranges for selectively detecting mTurquoise and mVenus fluorescence emissions. For our system, these ranges were determined to be 454 -494 for detection of mTurquoise and $520-580$ for detection of mVenus (Figure 1).

\section{System evaluation and optimization - spectral bleedthrough and fractional excitation (1.5-}

\section{2 hrs)}

CRITICAL: This protocol uses a single excitation wavelength $(810 \mathrm{~nm})$ to measure FRET standard and biosensor activity. The FRET standards are used for system validation, so it is necessary to determine the corrected EFRET for each standard excited at this wavelength (Step 21). This requires the measurement and removal of the DSBT and ASBT (steps 13 and 16 and Box 1). Since a single excitation wavelength is used, the determination of the ASBT also requires the estimation of the fractional excitation of Venus at $810 \mathrm{~nm}$. This is accomplished by measuring the average $\mathrm{I}_{\mathrm{Ch} 2-810} / \mathrm{I}_{\mathrm{Ch} 2-960}$ ratio from cells expressing a mixture of mTurquoise and mVenus (mTurquoise + mVenus), and the low FRET standard (Turquoise-TRAF-Venus, Step 16).

12| Collect images for measurement of SBT - Designate $810 \mathrm{~nm}$ as the illumination wavelength and select the optical configuration of the microscope system for optimal collection of CFP and YFP (determined in step 11A for users with filter-based systems) or set optical configuration according to the results obtained in step 11B (for users with spectral detection systems). Adjust laser power to fill the dynamic range of the detectors 
without saturation. Collect two-channel images from living cells expressing mTurquoise only and from cells expressing mVenus only (from step 8).

13| Image analysis for measurement of SBT. Using image-processing software (e.g., ImageJ, Metamorph, or the microscope manufacturer's software, identify regions-ofinterest in several cells expressing mVenus only and for each region measure the signal levels in the CFP and YFP channels. Correct these measurements for background by subtracting measurements obtained from nearby regions lacking fluorescence. For each cell, measure ASBT as the ratio of corrected measures obtained in the CFP channel to those obtained in the YFP channel. ASBT measurements are used to derive the correction factor A (Box 1), which is defined as the fraction of the signal in the acceptor channel that results from the direct excitation of mVenus at $810 \mathrm{~nm}$. ? Troubleshooting

14| Using image-processing software, identify regions-of-interest in several cells expressing mTurquoise only. For each region measure the signal levels in the CFP and YFP channels. The images are corrected for background by subtracting measurements obtained from nearby regions lacking fluorescence. For each cell, measure DSBT as the ratio of corrected measures obtained in the YFP channel to those obtained in the CFP channel. DSBT measures are used to derive the correction factor B (Box 1), which is defined as the fraction of the signal in the acceptor channel that results from the bleedthrough of the mTurquoise emission.

15| Collect images for measurement of fractional excitation of mVenus at $810 \mathrm{~nm}$. Using the same wavelengths, collect images of living cells expressing both mTurquoise and mVenus under conditions of minimal FRET (e.g., a mixture of the two, or a low-FRET 
standard, from step 8) first with illumination at $810 \mathrm{~nm}$, and then again using

illumination at $960 \mathrm{~nm}$. Laser power at $960 \mathrm{~nm}$ should be adjusted to be equivalent to that used at $810 \mathrm{~nm}$, as measured with a laser power meter at the specimen plane. ?

\section{Troubleshooting}

CRITICAL STEP: Tuning a titanium-sapphire laser to different wavelengths may lead to differences in laser alignment that can impact quantitative measures. It is critical to ensure that laser alignment is unaffected, or corrected, when changing between 810 and $960 \mathrm{~nm}$.

16| Image analysis for measuring fractional excitation of mVenus at $810 \mathrm{~nm}$. Using imageprocessing software (e.g., ImageJ, Metamorph or the microscope manufacturer's software), identify regions-of-interest in several cells expressing mVenus and for each region measure the signal levels in the YFP channels when excited at $810 \mathrm{~nm}$ and when excited at $960 \mathrm{~nm}$. Correct these measurements for background by subtracting measurements obtained from nearby regions lacking fluorescence. For each cell, measure the ratio of corrected signals obtained at $810 \mathrm{~nm}$ illumination to those measured at $960 \mathrm{~nm}$. This ratio is used, along with ASBT, to derive the correction factor A. The

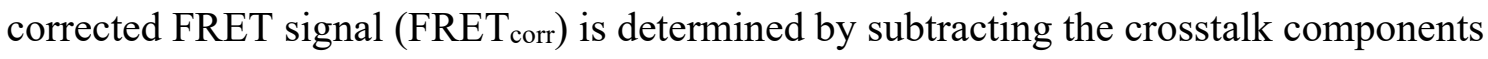
A and B from the raw FRET signal (donor excitation, acceptor emission (Box 1).

\section{System validation - Measure FRET in living cells expressing FRET-standard constructs -}

\section{3-4 hrs}

CRITICAL: The performance of the system is validated by measurement of FRET in cultured cells expressing the fully characterized FRET standard constructs. The determination of EFRET for the known FRET standards enables the user to assess the performance of their system, and 
to compare their results with those obtained here (or from other studies if different standards are used). To ensure that physiological measurements are not compromised by potential changes in the laser, optics, or detectors, data should be collected for FRET standards with each physiological study.

17I Image collection for measurements of FRET standards. 24 - $48 \mathrm{~h}$ prior to imaging, transfect HEK293 cells (as described in Steps 1-8) with the FRET standard constructs mTurquoise-TRAF-mVenus, mTurquoise-5AA-Venus, mTurquoise-10AA-Venus and a 1:1 mixture of mTurquoise and mVenus (see step 4).

18 Prepare the TPLSM system for imaging, as described in Step 9.

19| Transfer transfected cells into a medium suitable for maintaining physiological $\mathrm{pH}$ in air, or into a chamber capable of maintaining $5 \%(\mathrm{vol} / \mathrm{vol}) \mathrm{CO}_{2}$ environment. Mount cells in a stage incubator set to maintain cells at 37 degrees C. ? Troubleshooting

20| Using the same laser power and emission wavelength settings used in steps 12 and 15, collect two-channel images of cells expressing each of the FRET standard constructs and cells co-expressing mTurquoise and mVenus (see step 4).

CRITICAL STEP: Transient co-transfection of cells with a mixture of the mTurquoise and mVenus plasmids will produce highly variable relative expression levels of the two different FPs. For this protocol, it is important to pre-select cells for imaging that have intensity levels in both channels that are similar to the low FRET efficiency standard (mTurquoise-TRAFmVenus, which has a fixed 1:1 ratio of the donor and acceptor with little donor quenching). 
21 Image analysis for measurements of FRET standards. Using image-processing

software, identify regions-of-interest in several cells expressing fluorescent proteins and for each region measure the signal levels in the CFP and YFP channels. Correct these measurements for background by subtracting measurements obtained from nearby regions lacking fluorescence. For each cell, measure the FRET ratio and calculate EFRET (Box 1).

CRITICAL STEP: The 2PE method described here should readily distinguish the three FRET standards with the different linker lengths from one another based on the measured EFRET (see ANTICIPATED RESULTS). It is critical to use this approach to demonstrate that the TPLSM system is properly set up to obtain accurate measurements of EFRET, and is capable of high sensitivity measurements from the biosensor probes in living cells.

\section{Validate the FRET biosensor - Measure the biosensor probe FRET response in cultured cells - 5 hrs}

CRITICAL: It is important to validate the performance of the biosensor in a cell model prior to studies in more complex systems. The response of the biosensor probe is evaluated in living cells following treatment with agents known to stimulate the relevant physiological response pathway. Here, the PKA agonist forskolin (Fsk) is used to test the response of the AKAR4.1 biosensor to PKA activation.

22| Image collection for measurements of FRET biosensor responses. $24-48 \mathrm{~h}$ prior to imaging, transfect HEK293 cells with the FRET biosensor (here, AKAR4.1) as described in steps 1-8. 
23| Prepare the TPLSM system for imaging, as described in Step 9.

24| Transfer transfected cells into a medium suitable for maintaining physiological $\mathrm{pH}$ in air, or into a chamber capable of maintaining 5\% (vol/vol) CO2 environment. Mount cells in a stage incubator set to maintain cells at 37 degrees C. ? Troubleshooting

25| Using laser power and emission wavelength settings used in steps 12, 15 and 17, collect a series of two-channel images of a field of cells expressing AKAR4.1 to establish baseline measurements.

26| Collect a series of images before and after activating the biosensor probe. Here, images were collected at $30 \mathrm{sec}$ intervals before and after addition of Fsk to the culture medium (final concentration of $24 \mu \mathrm{M}$ ). Fsk-mediated activation of PKA is expected to induce a rapid and significant increase in the Venus to Turquoise emission ratio (see

\section{ANTICIPATED RESULTS).}

27| Image analysis for measurements of FRET biosensor responses. Using imageprocessing software, identify regions-of-interest in several cells expressing AKAR4.1 and for each region measure the signal levels in the CFP and YFP channels. Correct these measurements for background by subtracting measurements obtained from nearby regions lacking fluorescence. For each cell at each time point, measure the normalized Venus to Turquoise emission ratio.

CRITICAL STEP: It is important to verify the function of the FRET-based biosensor probes using other methods, such as fluorescence lifetime imaging microscopy or acceptor photobleaching measurements. Additionally, it is important to demonstrate that the biosensor is reporting the correct cellular activity. Treatment of cells with unrelated signaling molecules, or 
antagonists to the specific cellular pathway should not elicit the biosensor response. Moreover, point mutations in the bioactive linker (phosphorylation or binding sites) should abolish the changes in the probe response.

\section{Measure the biosensor probe FRET response in the organ of a living animal - Intravital microscopy - 7 hrs}

CRITICAL: Once the biosensor has been validated, the 2PE ratiometric method can be used to measure biosensor probe activity in the targeted organ in a living animal. Here, we demonstrate the approach by measuring the effect of glucagon on PKA activity in cells in the intact mouse liver in mice transduced with the Ad AKAR4.1 vector.

28 Transduction of mice with a FRET biosensor. 7 days prior to imaging, introduce $0.2 \mathrm{ml}$ of the Ad AKAR4.1 vector $\left(4.8 \times 10^{10}\right.$ particles $)$ into mice by tail vein injection, using standard methods (e.g., http://www.procedureswithcare.org.uk/intravenous-injection-inthe-mouse/).

Caution! - All animal studies must be approved by the Institutional Animal Care and Use Committee and must conform to the National regulations. Studies of animals transduced with adenovirus must be conducted in compliance with institutional biosafety standards.

29| Image collection of FRET biosensor responses in the liver of a living mouse. Physiological manipulations and animal preparations will vary according to the study. To prepare for activation of PKA in liver via glucagon ${ }^{53}$, withdraw food from mice $3 \mathrm{~h}$ prior to scheduled imaging. 
30| Prepare the TPLSM system for imaging, as described in Step 9.

31 Externalize the left lateral lobe of the liver and prepare for IVM imaging through a glass bottom plate using methods previously described ${ }^{24}$.

32| Place the animal on the warmed microscope stage, identify a field of hepatocytes expressing AKAR4.1 and, using the same microscope settings used in steps 12, 15, 17 and 26 , collect a series of 3D image volumes (10 planes spanning 10 microns) in CFP and YFP channels to establish the baseline ratio. 3D stacks are collected to ensure sequential capture of hepatocyte cytosols despite residual vertical motion of the liver because of respiration.

33| Continue to collect 3D image volumes during and following IP injection of glucagon $(200 \mu \mathrm{g} / \mathrm{kg})$ to monitor the increase in the FRET ratio resulting from activation in PKA.

34| Image analysis of FRET biosensor responses in the liver of a living mouse. Using image-processing software, align and assemble image stacks into a sum of all planes for each channel and each time point.

35| Identify regions-of-interest in several cells expressing AKAR4.1 that display relatively uniform fluorescence. For each region measure the signal levels in the CFP and YFP channels. Correct these measurements for background by subtracting measurements obtained from nearby regions lacking fluorescence. For each cell at each time point, measure the Venus to Turquoise emission ratio.

36| Pool and normalize the measured emission ratio data for all regions of interest. ? Troubleshooting

\section{TROUBLESHOOTING}


Troubleshooting advice can be found in Table 2 .

TIMING [Note from editor: please update and correct step numbers in section below to reflect changes to the Procedure]

Steps 1-8, Cell transfection: $\sim 1 \mathrm{~h}$, approximately $24-48 \mathrm{~h}$ prior to imaging

Steps 9-10, Prepare TPLSM system for imaging: $\sim 0.5 \mathrm{~h}$

Optional Step 11, Determine the spectra ranges of the detector channels; $\sim 1 \mathrm{~h}$

Steps 12, Image collection for measurement of SBT: $\sim 1 \mathrm{~h}$.

Steps 13-14, Image analysis for measurement of SBT: $\sim 1 \mathrm{~h}$.

Step 15, Image collection for measurement of fractional excitation of mVenus at $810 \mathrm{~nm}: \sim 1 \mathrm{~h}$

Step 16, Image analysis for measurement of fractional excitation of mVenus at $810 \mathrm{~nm}: \sim 1 \mathrm{~h}$

Steps 17-20, Image collection for measurement of FRET standards in cultured cells: $\sim 2 \mathrm{~h}$

Step 21, Image analysis for measurement of FRET standards in cultured cells: $\sim 4 \mathrm{~h}$

Steps 22-26, Image collection for measurement of FRET biosensor responses in cultured cells:

$\sim 2 \mathrm{~h}$

Step 27, Image analysis for measurement of FRET biosensor responses in cultured cells: $\sim 3 \mathrm{~h}$

Step 28, Transduction of mice with a FRET biosensor: $\sim 1 \mathrm{~h}$

Steps 29-33, Image collection for measurement of FRET biosensor responses in living mouse: $4 \mathrm{~h}$

Steps 34-36, Image analysis for measurement of FRET biosensor responses in living mouse: $\sim 4$

h

Box 1, Analysis of spectral bleedthrough for the determination of FRET efficiency: $\sim \mathrm{h}$

ANTICIPATED RESULTS 
Measurements of the FRET standards using 2PE. The FRET standards are used to demonstrate that the experimental model and microscope system are optimized for sensitive measurements of EFRET in living cells (Steps 17-21). If the SBT corrections are accurate (Box 1), then there should be very little energy transfer detected in cells that express a mixture of the unlinked mTurquoise and mVenus. The low FRET-efficiency standard, mTurquoise-TRAFmVenus should also have a low, but measurable EFRET $(\sim 5 \%)^{33,46,52}$. In contrast, measurements from the cells expressing the highest EFRET standard, mTurquoise-5AA-Venus produce EFRET of about $45 \%$. Critically, measurements from cells expressing the mTurquoise-10AA-Venus standard are expected to be about $36 \%$, and should be readily distinguishable from the FRET standard with the shorter linker (Figure 4). These FRET standards allow the validation of the imaging system, and provide a clear indication of the sensitivity of the measurements. The FRET standards also provide a control for identifying changes in performance of the laser, optics, or detectors that may compromise measurements under physiological conditions.

2PE measurements of FRET-based biosensor probe activities in cultured cells. Biosensor validation is accomplished in studies in cultured cells expressing the biosensor that are treated with established methods to activate the cell-signaling event. For our studies, we transfected HEK293 cells with AKAR4.1 and monitored emissions in the cyan (454 - $494 \mathrm{~nm})$ and yellow $(520-580 \mathrm{~nm})$ channels under illumination at $810 \mathrm{~nm}$ (Step 22-27). After collecting a series of baseline images, the PKA agonist forskolin (Fsk) was added to a final concentration of $24 \mu \mathrm{M}$. As expected, forskolin induced a rapid and pronounced (1.4-fold) increase in the emission ratio of Ven/Turq (Figure 5).

2PE measurements of FRET-based biosensor probe activities in living animals. After validation of the microscope system and the biosensor, studies are next conducted in living 
animals. For our studies, we took advantage of the robust tropism of adenovirus for the mouse liver following tail vein injection ${ }^{20}$ (Step 28). Seven days after injection with Ad AKAR4.1, the mice were fasted for $3 \mathrm{~h}$, prepared for IVM and then imaged as described above (Steps 29-33). Baseline images were collected, and imaging was continued after IP injection of glucagon (200 $\mu \mathrm{g} / \mathrm{kg}$ ), a treatment that has been previously shown to rapidly stimulate both cAMP and PKA in hepatocytes of fasted mice ${ }^{53}$. Similar to the results obtained with HEK-293 cells treated with Fsk, glucagon treatment in the living mouse induced a rapid 1.4 fold change in emission ratio of Ven/Turq (Figure 6), indicating a rapid and sustained activation of PKA. A certain degree of cell-cell variability can be expected from cells in vivo; our earlier measurements ${ }^{33}$ of 32 hepatocytes, from three separate studies ranged from 1.14 to 1.827 .

Note: Any Supplementary Information and Source Data files are available in the online version of the paper.

\section{ACKNOWLEDGMENTS}

This research is supported by the National Institutes of Health O'Brien Center for Advanced Renal Microscopic Analysis (NIH-NIDDK P30DK079312). The authors thank Dr. Malgorzata Kamocka and Seth Winfree for their assistance in microscopy. This paper is dedicated to the memory of Michael W. Davidson.

\section{AUTHOR CONTRIBUTIONS}

R.N.D. and K.W.D. wrote the manuscript. W.T. conducted the experiments, and R.N.D and K.W.D. supervised the research. Author RND is a leading expert in the field of fluorescent 
protein biosensors. Author KWD is one of the pioneers of intravital imaging in living animals using TPLSM.

\section{COMPETING FINANCIAL INTERESTS}

The authors declare no competing financial interests. 


\section{Box 1: Analysis of spectral bleedthrough for the determination of FRET efficiency. Digital Image Analysis - Timing $\sim 1.5 \mathrm{~h}$}

The optical pathway of the microscope system must be optimized for the detection of the mTurquoise-mVenus based biosensor probe when excited at $810 \mathrm{~nm}$. This is achieved by imaging cells that express either mTurquoise or mVenus alone (Procedure Steps 12-14). Spectral scanning on systems with spectral detectors, or careful selection of emission filters on filter-based systems will allow the user to adjust the optimal bandwidth for detection of the donor and acceptor signals (Procedure step 11). Once the donor and acceptor emission bandwidths are set, it is then necessary to measure the contributions of spectral bleedthrough (SBT) to the signals detected in the FRET channel (excitation $810 \mathrm{~nm}$, acceptor emission). The subtraction of the SBT signals from the signal that is detected in the FRET channel (FRET ${ }_{\text {raw }}$ ) provides the corrected FRET (FRET corr $)_{\text {signal }^{50}}$ :

$$
\mathrm{FRET}_{\text {corr }}=\mathrm{I}_{\text {FRET }}-\mathrm{A}^{*} \mathrm{I}_{\mathrm{FRET}}-\mathrm{B}^{*} \mathrm{I}_{\mathrm{Turq}}
$$

Correction for acceptor spectral bleedthrough (ASBT): The ASBT signal arises from the direct excitation of mVenus at $810 \mathrm{~nm}$. The correction factor $\mathbf{A}(\mathrm{Eq} 1)$ is used to remove ASBT. Measurements from cells expressing only mVenus are obtained using both $810 \mathrm{~nm}$ and $960 \mathrm{~nm}$ excitation to determine the fraction of the acceptor signal that arises from the direct excitation of mVenus at $810 \mathrm{~nm}$. For our system, we determined that the ASBT fraction was 0.030 . Because this protocol uses a single excitation wavelength (810 $\mathrm{nm}$ ) to measure FRET standard and biosensor activity, it is also necessary to approximate the intensity in the acceptor channel (Ch2-960) from the measurement at $810 \mathrm{~nm}$ (i.e., the fractional excitation of Venus at $810 \mathrm{~nm}$ ). This is accomplished by measuring the average 
ICh2-810/ICh2-960 ratio from cells expressing a mixture of mTurquoise and mVenus, and cells expressing the low-FRET standard (Turquoise-TRAF-Venus). For our system the average ratio was 0.344 . Therefore, multiplication of the acceptor intensity measured with excitation at $810 \mathrm{~nm}$ by $2.91(1 / 0.344)$ provides an approximation of the intensity in the acceptor channel to allow correction for ASBT. For our microscope system, the correction factor $\mathrm{A}$ is $2.91 \times 0.03=0.087$.

Correction for donor spectral bleedthrough (DSBT): The correction factor B (Eq 1) is used to remove DSBT, the signal detected in the acceptor channel that results from donor emission bleedthrough, and is determined from cells expressing only mTurquoise. Measurements from the donor-alone cells excited at $810 \mathrm{~nm}$ allowed us to determine the donor bleedthrough fraction was 0.295 on our system. Thus, the FRET corr can be determined by:

$2 \mathrm{PE} \mathrm{FRET} \mathrm{T}_{\text {corr }}=\mathrm{I}_{\text {FRET }}-0.087 * \mathrm{I}_{\mathrm{FRET}}-0.295 * \mathrm{I}_{\mathrm{Turq}}$

Determining FRET efficiency (ERET) for the FRET standards: The validation of the imaging system is accomplished by measurement of the FRET standards. Here, measurements are acquired from cells expressing a low EFRET standard (mTurquoiseTRAF-mVenus), and two high EFRET standards (mTurquoise-5AA-Venus and mTurquoise10AA-Venus) as described in ANTICIPATED RESULTS. The low EFret standard provides an indication of the threshold of detection, while the measurements from the two different high EFRET standards allow the user to assess the sensitivity of the system.

The EFRET is calculated as previously described ${ }^{33,50,51}$ using the equation: 


$$
\mathrm{E}=\mathrm{D}_{\text {lost }} / \mathrm{D}_{\text {total }}=\mathrm{D}_{\text {lost }} /\left(\mathrm{D}_{\text {lost }}+\mathrm{D}_{\text {remains }}\right)
$$

Where

$$
\mathrm{D}_{\text {lost }}=\mathrm{FRET}_{\text {corr }} *\left(\mathrm{QY}_{\mathrm{d}} / \mathrm{QY}_{\mathrm{a}}\right) *\left(\mathrm{~S}_{\mathrm{d}} / \mathrm{S}_{\mathrm{a}}\right) *\left(\mathrm{G}_{\mathrm{d}} / \mathrm{G}_{\mathrm{a}}\right)
$$

and

$$
\mathrm{D}_{\text {remains }}=\mathrm{I}_{\text {Turq- }}-810
$$

QY $\mathrm{d}$ and $\mathrm{QY}$ a denote the quantum yields of the donor and acceptor, respectively, where the quantum yield ratio for mTurquoise and mVenus is $1.474^{35,40}$. $\mathrm{S}_{\mathrm{d}}$ and $\mathrm{S}_{\mathrm{a}}$ denote the spectral sensitivities of the donor and acceptor channels. The $\mathrm{S}_{\mathrm{d}} / \mathrm{S}_{\mathrm{a}}$ ratio is approximated by the bandwidth ratio of channel 1 and channel 2. $\mathrm{G}_{\mathrm{d}}$ and $\mathrm{G}_{\mathrm{a}}$ are the detector gains for the donor and acceptor emission channels, and were set to a scaling factor of 1 for all measurements.

\section{END OF BOX 1}


Table 2| Troubleshooting table.

\begin{tabular}{|c|c|c|c|}
\hline Step & Problem & Possible reason & Solution \\
\hline $\begin{array}{l}12,15 \\
17,22\end{array}$ & $\begin{array}{l}\text { Cells do not adhere to the } \\
\text { cover slip properly, or they } \\
\text { are not healthy }\end{array}$ & $\begin{array}{l}\text { Cover slips are not coated } \\
\text { with appropriate matrix. } \\
\text { Inappropriate culture } \\
\text { conditions }\end{array}$ & $\begin{array}{l}\text { Coat cover slips with poly- } \\
\text { d-lysine or collagen. } \\
\text { Ensure that the culture } \\
\text { conditions are optimized } \\
\text { for the cell line used. }\end{array}$ \\
\hline $\begin{array}{l}12,15 \\
17,22\end{array}$ & $\begin{array}{l}\text { Inadequate expression of } \\
\text { fluorescent proteins in } \\
\text { cultured cells }\end{array}$ & $\begin{array}{l}\text { The transfection agent } \\
\text { (FuGENE, Lipofectamine, } \\
\text { X-tremGene HP) or DNA } \\
\text { plasmid concentration or } \\
\text { their ratio is not optimized }\end{array}$ & $\begin{array}{l}\text { Follow the transfection } \\
\text { agent manufacturer's } \\
\text { recommendations to vary } \\
\text { the ratio of DNA: } \\
\text { transfection agent or } \\
\text { concentrations of DNA } \\
\text { and/or transfection agent }\end{array}$ \\
\hline $\begin{array}{l}12,15 \\
17,22 \\
29\end{array}$ & Photobleaching is observed & $\begin{array}{l}\text { The power of the excitation } \\
\text { light is too high }\end{array}$ & $\begin{array}{l}\text { Optimize the optical path } \\
\text { and/or reduce laser power. }\end{array}$ \\
\hline $\begin{array}{l}12,15 \\
17,22 \\
29\end{array}$ & $\begin{array}{l}\text { The signal fluctuates } \\
\text { during TPLSM data } \\
\text { acquisition }\end{array}$ & $\begin{array}{l}\text { The laser illumination is } \\
\text { unstable. }\end{array}$ & $\begin{array}{l}\text { Ensure that laser is } \\
\text { warmed for } \sim 30 \text { min prior } \\
\text { to imaging. Ensure that } \\
\text { room temperature is stable. }\end{array}$ \\
\hline $\begin{array}{l}17,22, \\
29\end{array}$ & $\begin{array}{l}\text { FRET measurements are } \\
\text { obscured and/or altered by } \\
\text { cell or tissue } \\
\text { autofluorescence. }\end{array}$ & $\begin{array}{l}\text { Components in the specimen } \\
\text { have fluorescence excitation } \\
\text { properties at the donor } 2 \mathrm{PE} \\
\text { wavelength. }\end{array}$ & $\begin{array}{l}\text { Avoid media with } \\
\text { indicator dyes. Change } \\
\text { range of spectral detector } \\
\text { or change bandpass filter } \\
\text { for acceptor and/or donor } \\
\text { emissions to minimize } \\
\text { interference. Collect } \\
\text { images from FRET } \\
\text { standards expressed in the } \\
\text { same cells or tissues used } \\
\text { in studies of physiology. }\end{array}$ \\
\hline 11 & $\begin{array}{l}\text { Substantial bleedthrough of } \\
\text { the acceptor signal in the } \\
\text { donor channel is observed. }\end{array}$ & $\begin{array}{l}\text { Spectral bandwidth of donor } \\
\text { channel extends too far into } \\
\text { the range of the acceptor } \\
\text { emissions. Spectral } \\
\text { bandwidth of acceptor } \\
\text { channel is too wide or } \\
\text { inappropriate dichroic mirror } \\
\text { used. }\end{array}$ & $\begin{array}{l}\text { Change range of spectral } \\
\text { detector or change } \\
\text { bandpass filter for acceptor } \\
\text { and/or donor emissions. }\end{array}$ \\
\hline 11 & $\begin{array}{l}\text { Substantial bleedthrough of } \\
\text { the donor signal into the } \\
\text { acceptor channel. }\end{array}$ & $\begin{array}{l}\text { Spectral bandwidth of } \\
\text { acceptor channel extends too } \\
\text { far into the range of the }\end{array}$ & $\begin{array}{l}\text { Change range of spectral } \\
\text { detector or change } \\
\text { bandpass filter for acceptor }\end{array}$ \\
\hline
\end{tabular}




\begin{tabular}{|c|c|c|c|}
\hline & $\begin{array}{l}\text { Excessively high value of } \\
\text { correction factor "B". }\end{array}$ & $\begin{array}{l}\text { donor emissions or } \\
\text { inappropriate dichroic mirror } \\
\text { used. }\end{array}$ & and/or donor emissions. \\
\hline 21 & $\begin{array}{l}\text { Spatial variation in ratios } \\
\text { measured for the FRET } \\
\text { standards }\end{array}$ & $\begin{array}{l}\text { Chromatic aberration } \\
\text { Variable illumination across } \\
\text { the field } \\
\text { Variable background across } \\
\text { the field } \\
\text { Spatial variation in } \\
\text { photobleaching. }\end{array}$ & $\begin{array}{l}\text { Choose chromatically } \\
\text { corrected optical } \\
\text { components. } \\
\text { Ensure homogeneous } \\
\text { illumination; restrict } \\
\text { measurements to } \\
\text { homogenous region. } \\
\text { Use local background } \\
\text { subtraction for } \\
\text { quantifications. } \\
\text { Minimize illumination } \\
\text { levels, minimize time } \\
\text { spent identifying fields to } \\
\text { collect. }\end{array}$ \\
\hline 21 & $\begin{array}{l}\text { FRET standards fail to } \\
\text { produce the expected } \\
\text { EFRET. }\end{array}$ & $\begin{array}{l}\text { Low levels of probe } \\
\text { expression resulting in high } \\
\text { background contributions, } \\
\text { errors in image processing, } \\
\text { or errors in SBT corrections. } \\
\text { Deterioration of TPLSM } \\
\text { system performance. }\end{array}$ & $\begin{array}{l}\text { It is critical to verify the } \\
\text { FRET measurements of } \\
\text { the standards by multiple } \\
\text { methods (e.g., sensitized } \\
\text { emission, acceptor } \\
\text { photobleaching, } \\
\text { fluorescence lifetime) })^{33} \text {. } \\
\text { The different methods } \\
\text { should provide the same } \\
\text { EFRET for the standards. } \\
\text { If comparison with } \\
\text { previous studies indicates } \\
\text { a decline in the imaging } \\
\text { system performance, check } \\
\text { the optical path for } \\
\text { alignment issues, check all } \\
\text { filter settings, and measure } \\
\text { laser power at the } \\
\text { specimen plane to verify } \\
\text { that it is the same as } \\
\text { previous studies. If this } \\
\text { fails, call for microscope } \\
\text { service. }\end{array}$ \\
\hline 26,27 & Biosensor fails to respond & Cells are not healthy. & Ensure that cells are \\
\hline
\end{tabular}




\begin{tabular}{|c|c|c|c|}
\hline & $\begin{array}{l}\text { as expected to } \\
\text { physiological stimulation. }\end{array}$ & $\begin{array}{l}\text { Probe activator is ineffective. } \\
\text { Deterioration of TPLSM } \\
\text { system performance. }\end{array}$ & $\begin{array}{l}\text { healthy (see steps 1-2). } \\
\text { Ensure that probe activator } \\
\text { is fresh, appropriately } \\
\text { handled and used at the } \\
\text { correct concentration. } \\
\text { If comparison with } \\
\text { previous studies indicates } \\
\text { a decline in the imaging } \\
\text { system performance, check } \\
\text { the optical path for } \\
\text { alignment issues, check all } \\
\text { filter settings, and measure } \\
\text { laser power at the } \\
\text { specimen plane to verify } \\
\text { that it is the same as } \\
\text { previous studies. If this } \\
\text { fails, call for microscope } \\
\text { service. }\end{array}$ \\
\hline 29,36 & $\begin{array}{l}\text { Inadequate fluorescence } \\
\text { signal levels in animal. }\end{array}$ & $\begin{array}{l}\text { Inadequate expression of } \\
\text { fluorescent proteins. } \\
\text { Excessive depth-dependent } \\
\text { attenuation of fluorescence. }\end{array}$ & $\begin{array}{l}\text { Measure viral titer. } \\
\text { Reduce the depth of image } \\
\text { collection. Increase } \\
\text { illumination level. }\end{array}$ \\
\hline 29,36 & $\begin{array}{l}\text { Fluorescence image } \\
\text { decreases in intensity } \\
\text { and/or clarity over time. }\end{array}$ & $\begin{array}{l}\text { Water has evaporated from } \\
\text { water immersion objective. }\end{array}$ & $\begin{array}{l}\text { Replenish water more } \\
\text { frequently. Consider } \\
\text { switching to oil, glycerol } \\
\text { or silicon-oil immersion } \\
\text { objectives. }\end{array}$ \\
\hline
\end{tabular}




\section{REFERENCES}

1. Day, R.N. \& Davidson, M.W. The Fluorescent Protein Revolution (ed. Periasamy, A.) (Taylor \& Francis, Boca Raton, FL, 2014).

2. Zhang, J., Campbell, R.E., Ting, A.Y. \& Tsien, R.Y. Creating new fluorescent probes for cell biology. Nat Rev Mol Cell Biol 3, 906-18 (2002).

3. VanEngelenburg, S.B. \& Palmer, A.E. Fluorescent biosensors of protein function. Curr Opin Chem Biol 12, 60-5 (2008).

4. DiPilato, L.M. \& Zhang, J. Fluorescent protein-based biosensors: resolving spatiotemporal dynamics of signaling. Curr Opin Chem Biol 14, 37-42 (2010).

5. Miyawaki, A. Development of probes for cellular functions using fluorescent proteins and fluorescence resonance energy transfer. Annu Rev Biochem 80, 357-73 (2011).

6. Zhang, J., Ma, Y., Taylor, S.S. \& Tsien, R.Y. Genetically encoded reporters of protein kinase A activity reveal impact of substrate tethering. Proc Natl Acad Sci U S A 98, 14997-5002 (2001).

7. Patterson, G.H. \& Piston, D.W. Photobleaching in two-photon excitation microscopy. Biophys J 78, 2159-62 (2000).

8. Chen, T.S., Zeng, S.Q., Luo, Q.M., Zhang, Z.H. \& Zhou, W. High-order photobleaching of green fluorescent protein inside live cells in two-photon excitation microscopy. Biochem Biophys Res Commun 291, 1272-5 (2002).

9. Liu, L., Yermolaieva, O., Johnson, W.A., Abboud, F.M. \& Welsh, M.J. Identification and function of thermosensory neurons in Drosophila larvae. Nat Neurosci 6, 267-73 (2003).

10. Ben Arous, J., Tanizawa, Y., Rabinowitch, I., Chatenay, D. \& Schafer, W.R. Automated 
imaging of neuronal activity in freely behaving Caenorhabditis elegans. J Neurosci Methods 187, 229-34 (2010).

11. Kardash, E., Bandemer, J. \& Raz, E. Imaging protein activity in live embryos using fluorescence resonance energy transfer biosensors. Nat Protoc 6, 1835-46 (2011).

12. Hara, M. et al. Imaging endoplasmic reticulum calcium with a fluorescent biosensor in transgenic mice. Am J Physiol Cell Physiol 287, C932-8 (2004).

13. Kamioka, Y. et al. Live imaging of protein kinase activities in transgenic mice expressing FRET biosensors. Cell Struct Funct 37, 65-73 (2012).

14. Oldach, L. \& Zhang, J. Genetically encoded fluorescent biosensors for live-cell visualization of protein phosphorylation. Chem Biol 21, 186-97 (2014).

15. Aoki, K., Kamioka, Y. \& Matsuda, M. Fluorescence resonance energy transfer imaging of cell signaling from in vitro to in vivo: basis of biosensor construction, live imaging, and image processing. Dev Growth Differ 55, 515-22 (2013).

16. Berglund, K. et al. Imaging synaptic inhibition in transgenic mice expressing the chloride indicator, Clomeleon. Brain Cell Biol 35, 207-28 (2006).

17. Haustein, M.D. et al. Conditions and constraints for astrocyte calcium signaling in the hippocampal mossy fiber pathway. Neuron 82, 413-29 (2014).

18. Madisen, L. et al. Transgenic mice for intersectional targeting of neural sensors and effectors with high specificity and performance. Neuron $\mathbf{8 5}, 942-58$ (2015).

19. Johnsson, A.K. et al. The Rac-FRET mouse reveals tight spatiotemporal control of Rac activity in primary cells and tissues. Cell Rep 6, 1153-64 (2014).

20. Buchholz, C.J., Friedel, T. \& Buning, H. Surface-Engineered Viral Vectors for Selective and Cell Type-Specific Gene Delivery. Trends Biotechnol 33, 777-90 (2015). 
21. Babbey, C.M., Ryan, J.C., Gill, E.M., Ghabril, M.S., Burch, C.R., Paulman, A., Dunn, K.W. Quantitative intravital microscopy of hepatic transport. Intravital 1, 44-53 (2012).

22. Dunn, K.W. et al. Functional studies of the kidney of living animals using multicolor two-photon microscopy. Am J Physiol Cell Physiol 283, C905-16 (2002).

23. Dunn, K.W., Sutton, T.A. \& Sandoval, R.M. Live-animal imaging of renal function by multiphoton microscopy. Curr Protoc Cytom Chapter 12, Unit12 9 (2007).

24. Ryan, J.C., Dunn, K.W. \& Decker, B.S. Effects of chronic kidney disease on liver transport: quantitative intravital microscopy of fluorescein transport in the rat liver. Am J Physiol Regul Integr Comp Physiol 307, R1488-92 (2014).

25. Presson, R.G., Jr. et al. Two-photon imaging within the murine thorax without respiratory and cardiac motion artifact. Am J Pathol 179, 75-82 (2011).

26. Vinegoni, C. et al. Sequential average segmented microscopy for high signal-to-noise ratio motion-artifact-free in vivo heart imaging. Biomed Opt Express 4, 2095-106 (2013).

27. Dombeck, D.A., Khabbaz, A.N., Collman, F., Adelman, T.L. \& Tank, D.W. Imaging large-scale neural activity with cellular resolution in awake, mobile mice. Neuron 56, 43-57 (2007).

28. Dunn, K.W., Lorenz, K.S., Salama, P. \& Delp, E.J. IMART software for correction of motion artifacts in images collected in intravital microscopy. Intravital 3, e28210 (2014).

29. Lee, S., Vinegoni, C., Sebas, M. \& Weissleder, R. Automated motion artifact removal for intravital microscopy, without a priori information. Sci Rep 4, 4507 (2014).

30. Lorenz, K.S., Salama, P., Dunn, K.W. \& Delp, E.J. Digital correction of motion artefacts 
in microscopy image sequences collected from living animals using rigid and nonrigid registration. J Microsc 245, 148-60 (2012).

31. Soulet, D., Pare, A., Coste, J. \& Lacroix, S. Automated filtering of intrinsic movement artifacts during two-photon intravital microscopy. PLoS One 8, e53942 (2013).

32. Radbruch, H. et al. Intravital FRET: Probing Cellular and Tissue Function in Vivo. Int $J$ Mol Sci 16, 11713-27 (2015).

33. Tao, W. et al. A practical method for monitoring FRET-based biosensors in living animals using two-photon microscopy. Am J Physiol Cell Physiol 309, C724-35 (2015).

34. Shaner, N.C. et al. Improving the photostability of bright monomeric orange and red fluorescent proteins. Nat Methods 5, 545-51 (2008).

35. Goedhart, J. et al. Bright cyan fluorescent protein variants identified by fluorescence lifetime screening. Nat Methods 7, 137-9 (2010).

36. Goedhart, J. et al. Structure-guided evolution of cyan fluorescent proteins towards a quantum yield of 93\%. Nat Commun 3, 751 (2012).

37. Markwardt, M.L. et al. An improved cerulean fluorescent protein with enhanced brightness and reduced reversible photoswitching. PLoS One 6, e17896 (2011).

38. Zipfel, W.R., Williams, R.M. \& Webb, W.W. Nonlinear magic: multiphoton microscopy in the biosciences. Nat Biotechnol 21, 1369-77 (2003).

39. Rizzo, M.A., Springer, G., Segawa, K., Zipfel, W.R. \& Piston, D.W. Optimization of pairings and detection conditions for measurement of FRET between cyan and yellow fluorescent proteins. Microsc Microanal 12, 238-54 (2006).

40. Nagai, T. et al. A variant of yellow fluorescent protein with fast and efficient maturation for cell-biological applications. Nat Biotechnol 20, $87-90$ (2002). 
41. Thaler, C., Koushik, S. V., Blank, P. S. \& Vogel, S. S. Quantitative multiphoton spectral imaging and its use for measuring resonance energy transfer. Biophys $J$ 89, 2736-2749.

42. Zhou, X., Herbst-Robinson, K.J. \& Zhang, J. Visualizing dynamic activities of signaling enzymes using genetically encodable FRET-based biosensors from designs to applications. Methods Enzymol 504, 317-40 (2012).

43. Rincon, M.Y., VandenDriessche, T. \& Chuah, M.K. Gene therapy for cardiovascular disease: advances in vector development, targeting, and delivery for clinical translation. Cardiovasc Res 108, 4-20 (2015).

44. McGhee, E. J. et al. FLIM-FRET imaging in vivo reveals 3D-environment spatially regulates RhoGTPase activity during cancer cell invasion. Small GTPases 2, 239-244, doi:10.4161/sgtp.2.4.17275 (2011).

45. Nobis, M. et al. Intravital FLIM-FRET imaging reveals dasatinib-induced spatial control of src in pancreatic cancer. Cancer research 73, 4674-4686, doi:10.1158/00085472.CAN-12-4545 (2013).

46. Janssen, A., Beerling, E., Medema, R. \& van Rheenen, J. Intravital FRET imaging of tumor cell viability and mitosis during chemotherapy. PLoS One 8, e64029, doi:10.1371/journal.pone.0064029 (2013).

47. Thestrup, T. et al. Optimized ratiometric calcium sensors for functional in vivo imaging of neurons and T lymphocytes. Nat Methods 11, 175-82 (2014).

48. Luo, J. et al. A protocol for rapid generation of recombinant adenoviruses using the AdEasy system. Nat Protoc 2, 1236-47 (2007).

49. Miller, R.A. et al. Biguanides suppress hepatic glucagon signaling by decreasing production of cyclic AMP. Nature 494, 256-60 (2013). 
50. Day, R.N. Measuring protein interactions using Forster resonance energy transfer and fluorescence lifetime imaging microscopy. Methods 66, 200-207 (2014).

51. Broussard, J.A., Rappaz, B., Webb, D.J. \& Brown, C.M. Fluorescence resonance energy transfer microscopy as demonstrated by measuring the activation of the serine/threonine kinase Akt. Nat Protoc 8, 265-81 (2013).

52. Periasamy, A. \& Day, R.N. Molecular Imaging: FRET Microscopy and Spectroscopy (Oxford University Press, New York, 2005). 


\section{FIGURE LEGENDS}

Figure 1| Schematic overview of the Procedure to measure biosensor activity in the living animal. Following viral transduction of a biosensor probe in mice, the procedure is used to monitor the activity of the probe in the anesthetized animal. The procedure uses selective $2 \mathrm{PE}$ of mTurquoise at $810 \mathrm{~nm}$ to make ratiometric FRET measurements in vivo. To image probe activity in the liver, the left lateral lobe of the liver was carefully lifted and secured to a glass bottom plate. The mouse is then placed ventral side down on a heated microscope stage and covered with a warming blanket, and the liver is imaged using a long working-distance waterimmersion objective.

Figure 2| Diagram of the flow of the Procedure. The Procedure starts with transfection of cells (Procedure steps 1-8) with a series of standards that are used to evaluate and optimize the TPLSM system, and to determine the SBT components when using $2 \mathrm{PE}$ at $810 \mathrm{~nm}$ (Procedure steps 10-16). Then, the FRET standards are used to evaluate the sensitivity of the system for the accurate measurement of EFRET (Procedure steps 17-21). The biosensor probe of interest is then verified in a cell model by measuring changes in the Venus to Turquoise ratio over time in response to suitable activators of the targeted signaling pathway (Procedure steps 22-27). Once the system and biosensor have been verified, studies in the living animal are conducted (Procedure steps 28-36).

Figure 3| 2PE spectral scanning of the indicated FPs expressed individually in living HEK293 cells. The relative $2 \mathrm{PE}$ spectral scans for (a) mTurquoise and (b) mVenus, were acquired from living cells by measuring fluorescence emissions over a range of excitation wavelengths at 
a constant laser power and a detector scaling factor of 1; the red bar indicates excitation at 810 $\mathrm{nm}$ used in this protocol. In order to provide fluorescence excitation spectra that are independent of variations at the output of the laser at different wavelengths, spectral variation in laser power was eliminated by adjusting laser power to a constant value at each wavelength, as measured using a PM100D power meter with $\lambda$ correction (Thorlabs, Newton, NJ), mounted on the microscope stage $\mathrm{e}^{33}$. The emission signals at the different excitation wavelengths were simultaneously detected in channel 1 (cyan, $454-494 \mathrm{~nm}$ ) and channel 2 (yellow, $520-580$ $\mathrm{nm})$, and the images are acquired at each wavelength step as described in the Experimental Design. [Adapted from ref 33]

Figure 4| FRET ratio images of HEK-293 cells expressing the indicated FRET standard probes. Cells were excited by illumination at $810 \mathrm{~nm}$ and the mTurquoise (donor) intensity was measured in channel 1(454-494 nm), while mVenus (acceptor) intensity was measured in channel $2(520-580 \mathrm{~nm})$. The FRET ratio images obtained from representative cells expressing the different FRET standard fusion proteins are shown (scale bar is $10 \mu \mathrm{m}$ ). [Adapted from ref 33]

Figure 5| Ratiometric FRET measurements from HEK-293 cells expressing the AKAR4.1 biosensor probe. The cells are illuminated at $810 \mathrm{~nm}$ and the emission signals are simultaneously measured in the mTurquoise (donor) channel $(454-494 \mathrm{~nm})$ and the mVenus (acceptor) channel $(520-580 \mathrm{~nm})$. The cells were treated with protein kinase A (PKA) activator Forskolin (Fsk) to elicit changes in the FRET signal from the AKAR4.1 biosensor 
probe. (a) FRET ratio images of cells prior to (pre-treatment) and 3 min after Fsk treatment (scale bar is $10 \mu \mathrm{m}$ ). (b) The cells were treated with Forskolin (Fsk) at time zero and the acceptor to donor ratio (Ven/Turq) was measured every thirty seconds for ten minutes. The Ven/Turq ratio was determined from eleven cells $( \pm \mathrm{SE})$ as described in Box 1. [Adapted from ref 33]

Figure 6| Using TPLSM to measure the response of the AKAR4.1 biosensor to glucagon in hepatocytes in the intact mouse liver. The Ad AKAR4.1 viral particles were introduced by tail vein injection, and resulted in extensive expression in the liver 7 days later. (a) Ratio images from a single image plane in mouse liver at the indicated time points (scale bar is $10 \mu \mathrm{m})$. (b) The mouse was treated by IP injection with glucagon $(200 \mu \mathrm{g} / \mathrm{kg})$ at time zero and the acceptor to donor ratio (Ven/Turq) was measured every fifteen seconds for ten minutes. The Ven/Turq ratio was determined as described in Box 1, and the results are from the 10 individual cells ( \pm SE). [Adapted from ref 33] All animal studies were approved by the Indiana University School of Medicine Institutional Animal Care and Use Committee and conform to the "Guide for the Care and Use of Laboratory Animals" published by the National Institutes of Health (NIH Publication No. 85-23, Revised 1996).

\section{Supplementary Information}

Supplementary Sequence Archive. DNA sequence information for plasmids used in this protocol (see Table 1). 
Figure 1.

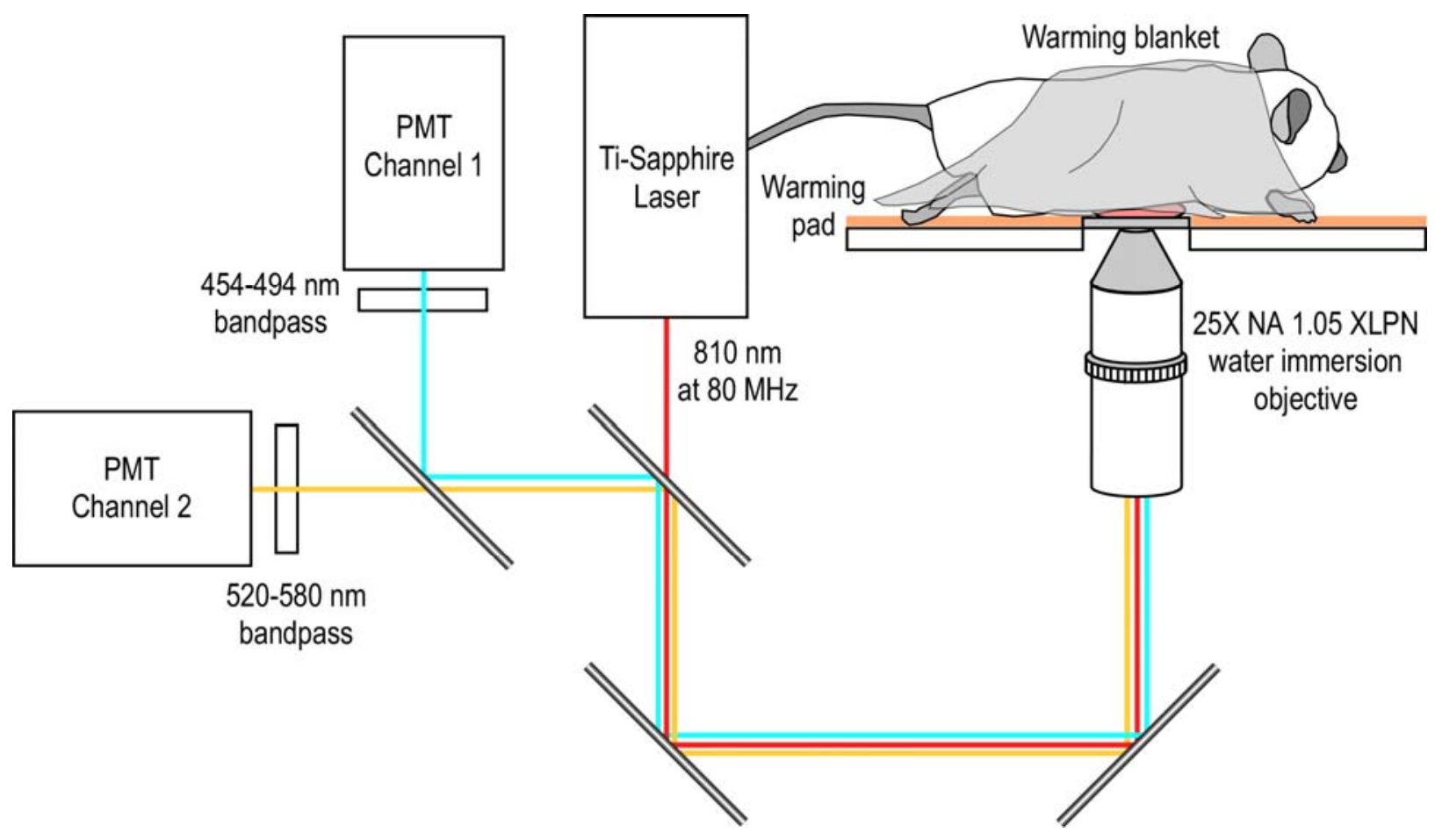


Figure 2.

Steps 1-9

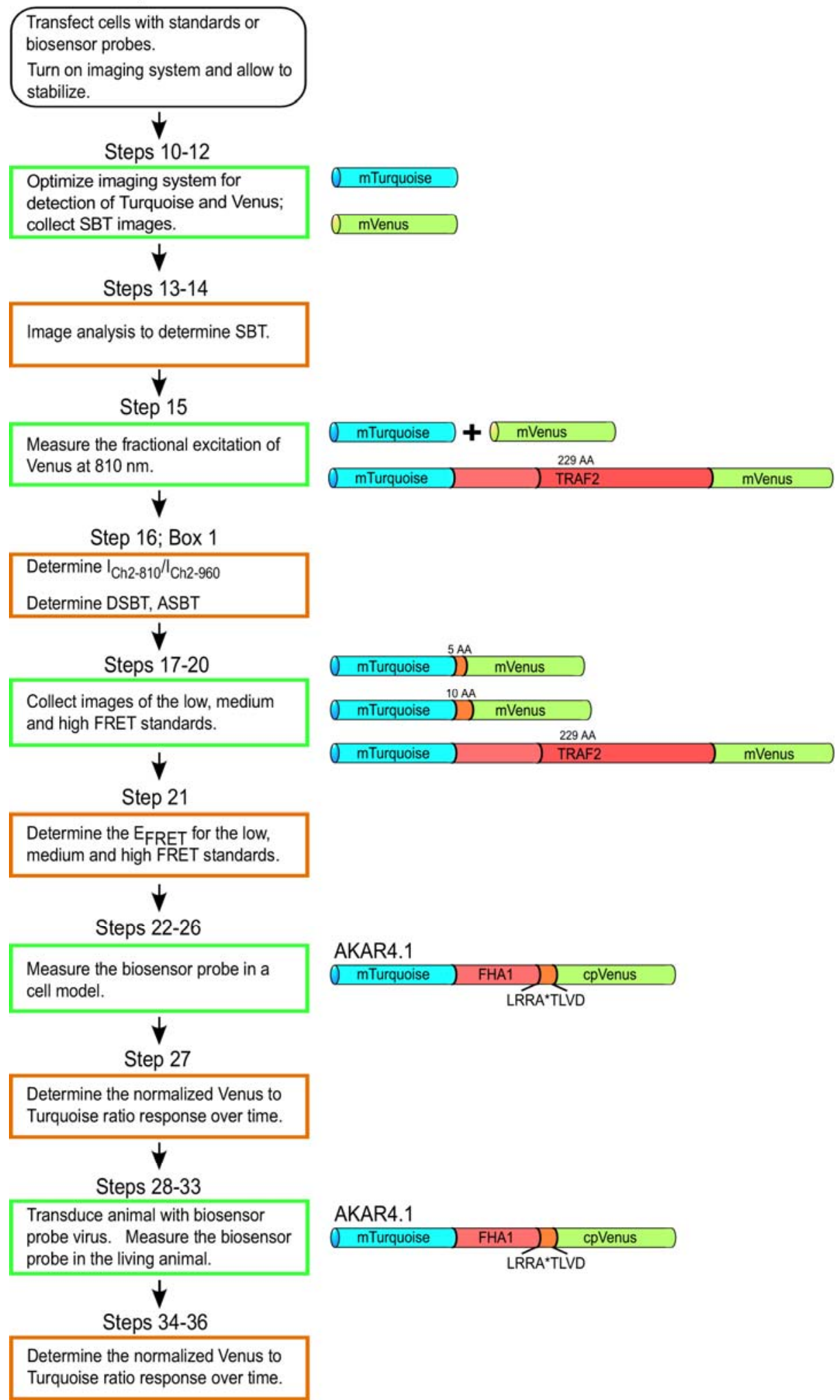


Figure 3.

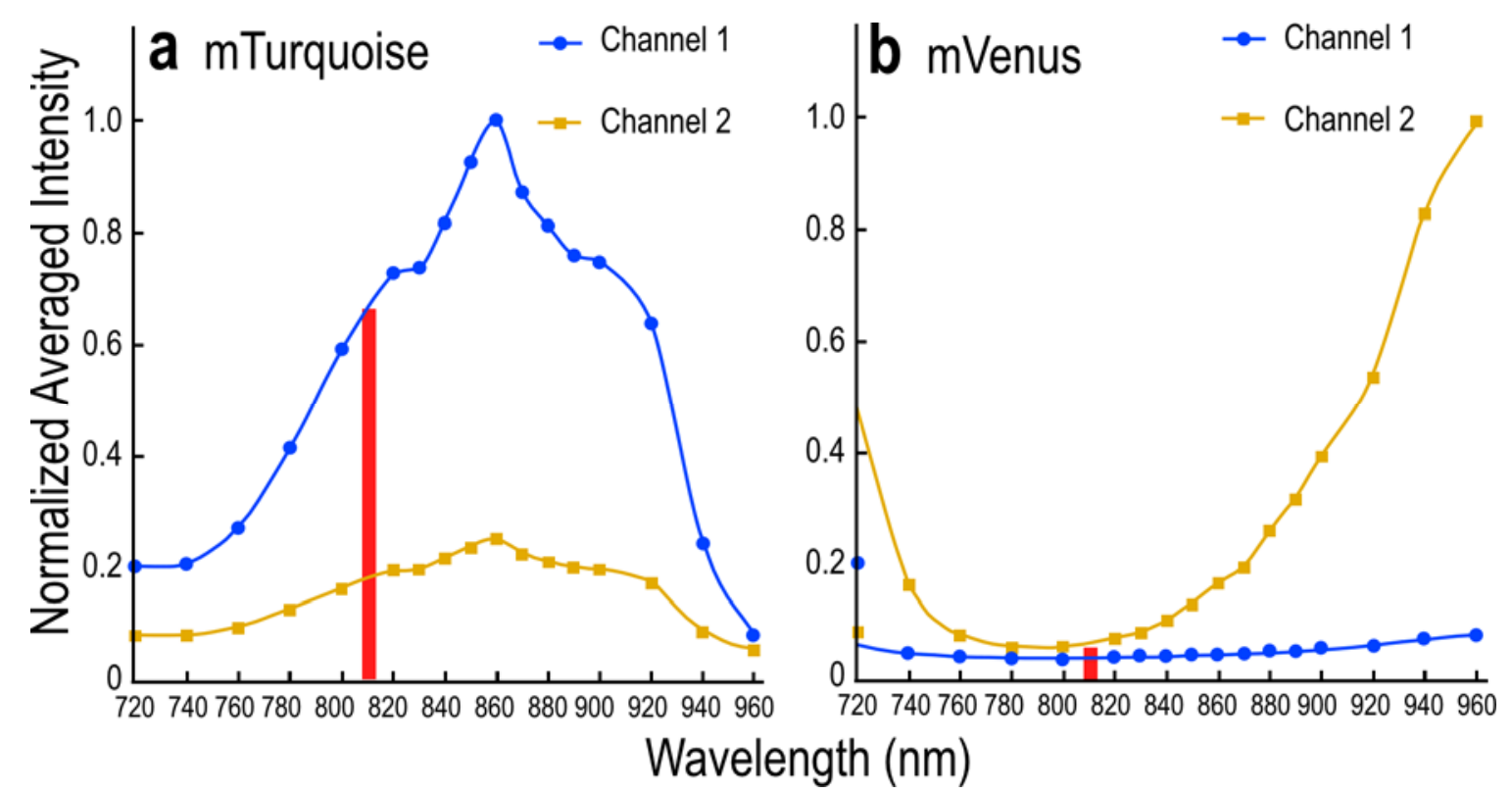


Figure 4.

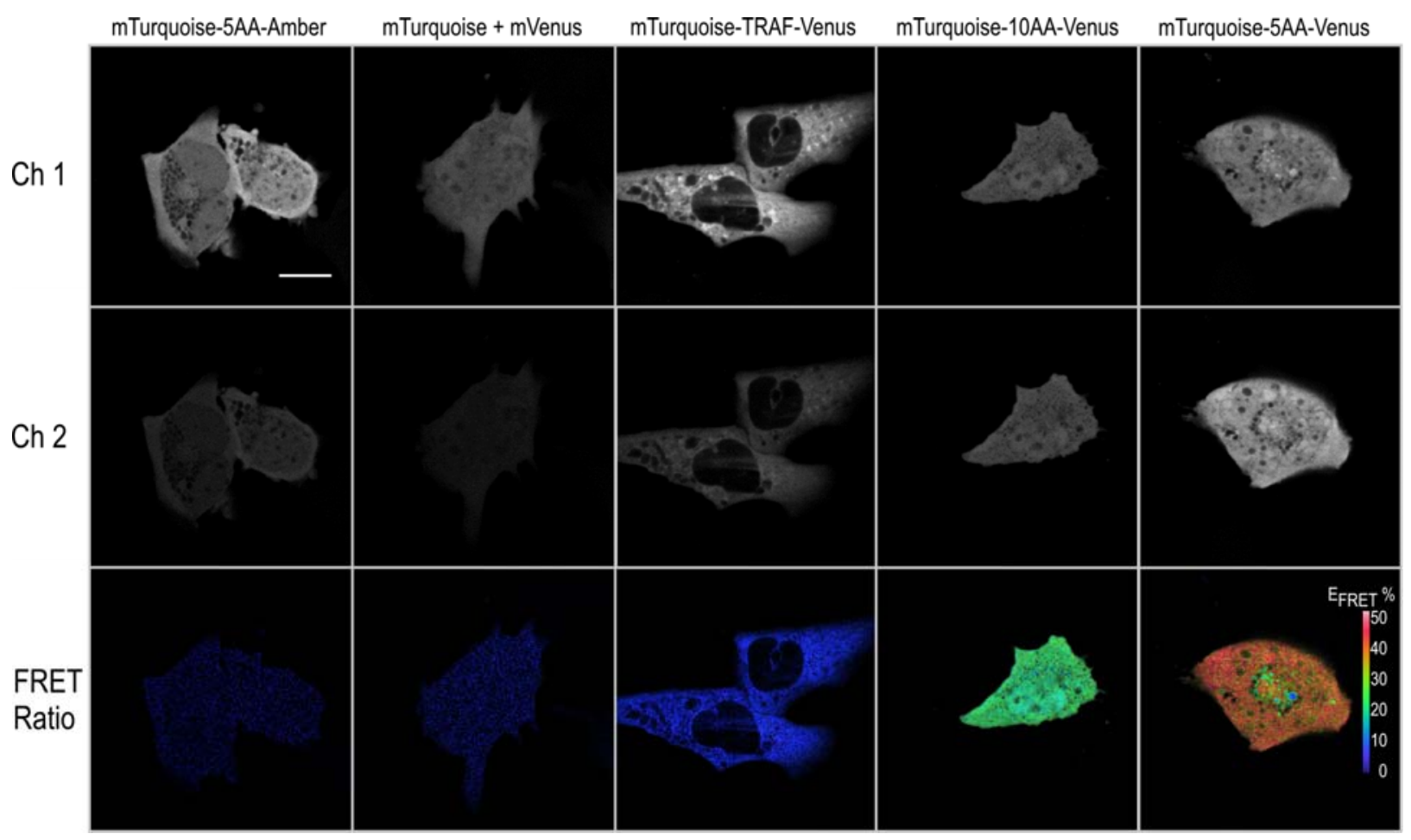


Figure 5.
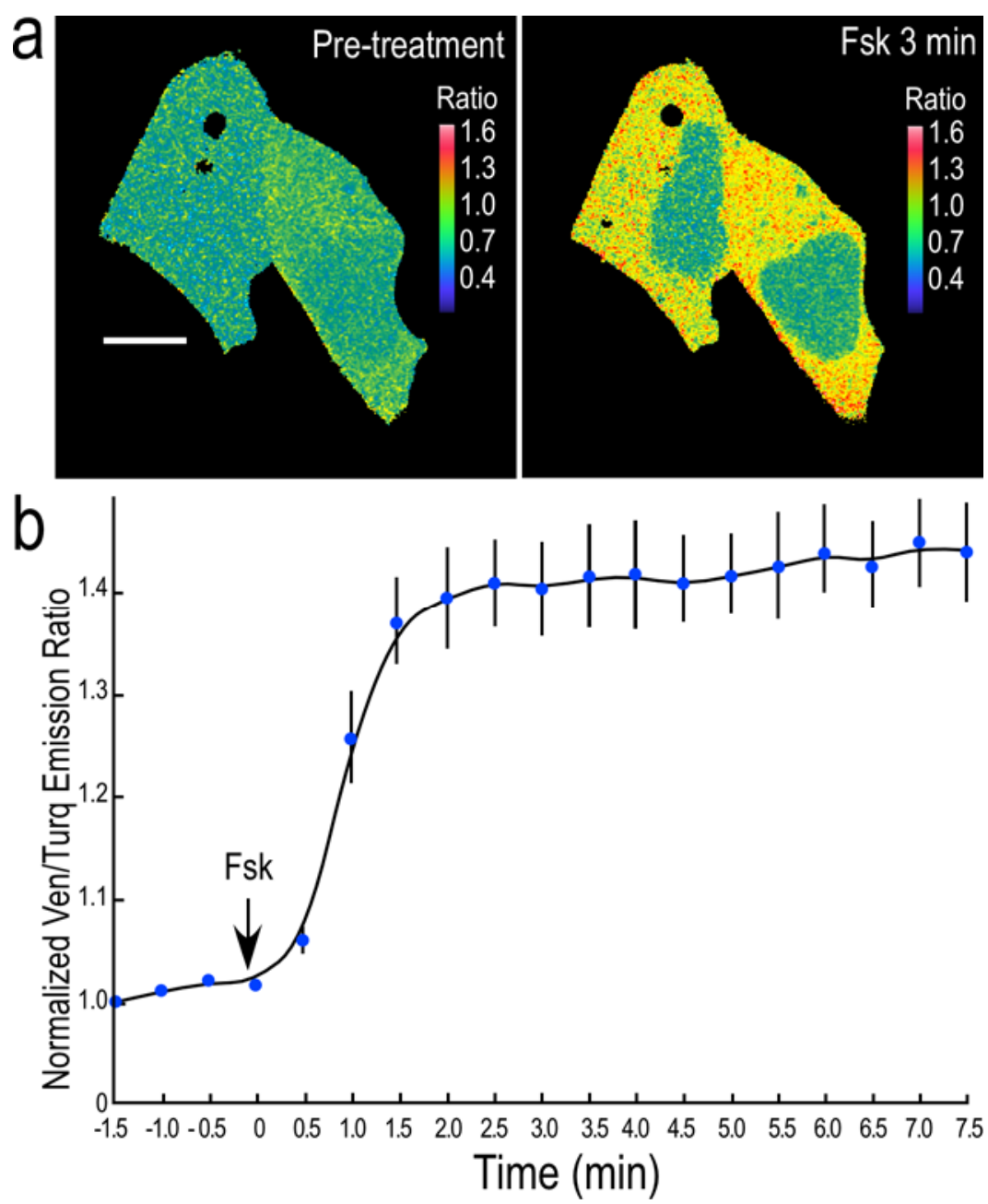
Figure 6.

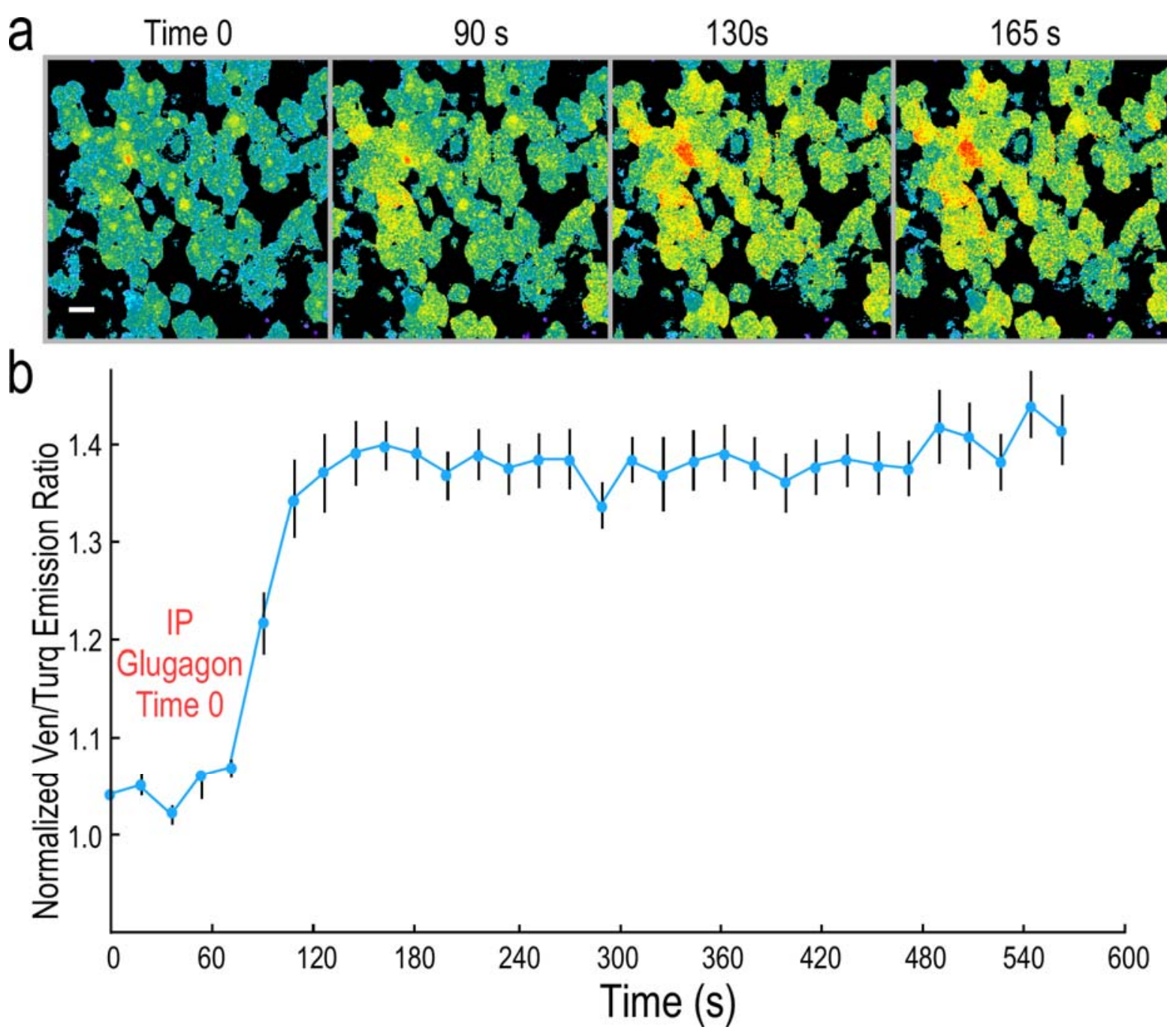

